\title{
Evaluasi Pengangkutan Tandan Buah Segar Kelapa Sawit terhadap Buah Restan di PT. Dwiwira Lestari Jaya
}

\author{
Evaluation of the Transportation of Palm Fruit Fresh Bunches against Restan Fruit in PT. \\ Dwiwira Lestari Jaya
}

\author{
Nurfara Rasyika*, Rossy Mirasari, Faradilla \\ Politeknik Pertanian Negeri Samarinda, Jl. Samratulangi, Samarinda, Indonesia
}

${ }^{*}$ Corresponding Author: nurfara.rasyika@gmail.com

\begin{abstract}
Abstrak
Pada industri pengolahan kelapa sawit, keterlambatan pengangkutan Tandan Buah Segar (TBS) perlu dihindari karena dapat mempengaruhi kualitas produksi akhir, kualitas produksi sangat bergantung pada kecepatan transportasi, optimalisasi transportasi yang tidak tepat dapat menyebabkan kegiatan di lapangan menjadi tidak lancar. Penelitian ini bertujuan untuk mengetahui kebutuhan dan realisasi ketersediaan unit angkutan TBS di lapangan dan untuk mengetahui faktor penyebab terjadinya restan buah. Penelitian dilakukan pada perkebunan kelapa sawit PT. Dwiwira Lestari Jaya (DLJ), divisi Charlie yang berlokasi di Desa Biatan Ilir, Kecamatan Biatan, Kabupaten Berau, Provinsi Kalimantan Timur. Penelitian ini dilakukan selama 1 bulan terhitung mulai tanggal 1 Oktober sampai dengan 31 Oktober 2020. Penelitian ini menggunakan metode dengan mengambil data primer berupa observasi lapangan dan dokumentasi, dan data sekunder berupa dokumen perusahaan dan studi pustaka. Analisis data yang penulis gunakan adalah analisis statistik deskriptif untuk menggambarkan atau mendeskripsikan data yang telah terkumpul. Hasil penelitian yang dilakukan pada PT. Dwiwira Lestari Jaya menunjukkan jumlah unit angkut TBS per divisi sesuai dengan perhitungan kebutuhan adalah 2 unit angkut TBS, serta beberapa hal yang mempengaruhi kinerja transportasi yaitu kondisi alat angkut, jumlah tenaga angkut. , kondisi pabrik kelapa sawit, kondisi jalan, dan curah hujan mempengaruhi kinerja transportasi yang menyebabkan buah restan.
\end{abstract}

Kata Kunci : tandan buah segar, restan buah, transportasi

\begin{abstract}
Delays in the transportation of Fruit Fresh Bunches (FFB) needs to be avoided because it will affect the quality of final production, the quality of production is very dependent on the speed of transportation, improper optimization of transportation can cause activities in the field to be hampered. This research aims to find out the needs and realization of the availability of FFB transport units in the field and to find out the factors that cause restan fruit. The research was conducted on oil palm plantations of PT. Dwiwira Lestari Jaya (DLJ), Charlie's division located in Biatan Ilir Village, Subdistrict Biatan, Regency Berau, East Borneo Province. This study was conducted for 1 month, starting from October 1 to October 31, 2020. This research uses methods by taking primary data in the form of field observations and documentation, and secondary data in the form of company documents and literature studies. The data analysis that the author uses is descriptive statistical analysis to describe or describe the data that has been collected. The results of research conducted at PT. Dwiwira Lestari Jaya showed that the number of FFB transport units per division in accordance with the calculation of needs is 2 FFB transport units, as well as several things that affect the performance of transportation, namely the condition of transport equipment, the number of transport workers, palm oil factory conditions, road conditions, and rainfall affect the performance of transportation that causes restan fruit.
\end{abstract}

Keywords : fruit fresh buncht, restan fruit, transportation

\section{PENDAHULUAN}

Tandan Buah Sawit (TBS) adalah bahan utama dari proses produksi pabrik yang bersifat rentan busuk, sehingga harus segera diangkut ke Pabrik Kelapa Sawit (PKS). Penumpukan buah di Tempat Pengumpulan
Hasil (TPH) yang sudah dipotong dan tidak segera diangkut dapat meningkatkan Asam Lemak Bebas (ALB), untuk itu sangat diperlukan persiapan kebutuhan alat pengangkutan yang baik. Untuk keberhasilan pengangkutan TBS perlu adanya koordinasi 
antara bagian kebun, bagian angkut, dan bagian pabrik menjadi sangat penting guna menyelaraskan sirkulasi pengangkutan buah agar lebih efektif dalam waktu dan menghemat biaya produksi (Saragi, 2019). Pengangkutan TBS adalah salah satu kegiatan dalam pemanenan. Pengangkutan hasil produksi buah kelapa sawit perlu perhatian lebih untuk menjaga kualitas dan rendeman minyak. Keterlambatan pengolahan TBS menjadi minyak akan meningkatkan kandungan ALB pada buah. Sarana dan prasarana pada transportasi yang baik sangat diperlukan pada kegiatan pengangkutan ini, agar dapat menjamin buah tidak mengalami keterlambatan. Jika buah kelapa sawit masuk PKS dalam jangka waktu lebih dari 24 jam setelah buah tersebut dipanen, maka dapat disebut sebagai buah restan, dan buah restan mengandung ALB yang tinggi (Dhani, 2014).

Menurut Lukito dan Sudradjat (2017), mutu CPO dapat dilihat secara kuantitas dan kualitas. Produksi buah dengan kuantitas baik akan menghasilkan rendemen $\mathrm{CPO}$ 23.2-27.4\% dengan kadar ALB atau FFA < $3 \%$. Rendemen minyak yang tinggi didapatkan dengan cara mengolah buah kelapa sawit yang matang (ripe), karena buah yang matang memiliki kandungan minyak terbanyak daripada jenis atau kelompok mutu buah lainnya. Buah matang diperoleh dari kegiatan panen atau potong buah sehingga mengharuskan pemanen untuk mengutamakan momotong buah matang dengan jumlah paling banyak (> 98\%) agar hasil ekstraksi minyak (rendemen CPO) tinggi. Semakin tinggi kandungan FFA, maka semakin rendah kualitas CPO. Pengaruh rendah atau tingginya FFA dan rendemen CPO terletak pada mutu buah yang dipanen. Mutu buah yang baik akan menghasilkan CPO dengan FFA rendah dan rendemen minyak yang tinggi. Buah yang terlambat diolah akibat terlambat pengangkutan(restan) dapat meningkatkan FFA, selain itu penanganan yang kasar juga dapat meningkatkan laju FFA. Luka pada buah kelapa sawit akibat penanganan yang kasar dapat menstimulasi konversi molekul minyak menjadi FFA dengan laju yang sangat tinggi, sehingga kandungan FFA meningkat dengan cepat. Pembentukan FFA terbanyak adalah saat di lapangan atau sebelum mulai diolah di PKS, karena pada saat pengolahan di PKS kenaikan FFA hanya $0.1 \%$ atau paling tinggi $0.3-0.5 \%$ pada PKS yang kurang terkendali pengawasannya. Kenaikan FFA saat penimbunan dan pengapalan hingga sampai di tangan konsumen juga relatif rendah .

Dalam pengolahan kelapa sawit, faktor transportasi mendapatkan perhatian khusus. Keterlambatan pengakutan TBS ke PKS akan mempengaruhi proses pengolahan, kapasitas olah dan mutu prduksi akhir. Pengakutan buah kelapa sawit dari kebun ke pabrik harus dilakukan secepat mungkin agar buah yang dipanen hari ini dapat diolah langsung sehingga asam lemak bebas tidak tinggi. Perusahaan perkebunan kelapa sawit yang sudah mampu mengolah semua pekerjaan dengan baik dan kebun tersebut sudah mapan, makan presentase penyediaan angkutan buah $75 \%-85 \%$ Sistem jaringan jalan di perkebunan juga merupakan salah satu faktor penting untuk kelancaran pengakutan TBS ke pabrik. Banyak pekerjaan di suatu areal atau blok tidak dapat dilaksanakan dengan lancar karena prasarana jalan atau jembatan tidak memadai sehingga kegiatan operasional jadi terlambat. Melihat pentingnya transportasi di perkebunan kelapa sawit maka perawatan dan cara perbaikan kendaraan atau alat berat yang merupakan sarana yang harus diperhatikan sehingga kendaraan tersebut dapat berfungsi dengan baik pada saat dibutuhkan. Pelaksanaan panen dan pengangkutannya ke PKS menyakut sejumlah aspek yang kesemuanya berpengaruh nyata baik terhadap kuantitas maupun kualitas minyak yang akan diperoleh. Setiap aspek bersifat kompleks, lebih-lebih bila dipertimbangkan keterkaitan diantara aspek-aspek tersebut (Fadillah, 2013).

Tujuan dari penelitian ini adalah untuk mengetahui kebutuhan dan realisasi ketersediaan unit pengangkut TBS di lapangan serta untuk mengetahui faktorfaktor penyebab buah restan.

\section{METODE PENELITIAN}

\section{Tempat dan Waktu}

Penelitian dilaksanakan pada perkebunan kelapa sawit PT. Dwiwira Lestari Jaya (DLJ), afdeling Charlie yang terletak di Kampung Biatan Ilir, Kecamatan Biatan, 
Kabupaten Berau, Provinsi Kalimantan Timur. Penelitian ini dilaksanakan selama 1 bulan, terhitung mulai tanggal 1 Oktober sampai 31 Oktober 2020, meliputi observasi lapangan dan pengambilan data.

\section{Alat dan Bahan}

Alat dan bahan yang digunakan dalam penelitian ini adalah sebagai berikut : Alat Handphone, Laptop, Alat tulis dan GPS. Bahan Dokumen/arsip perusahaan yang menunjang penelitian dan literatur/pustaka.

\section{Metode Pengumpulan Data}

Metode pengambilan data yang digunakan dalam penelitian ini adalah data primer dan data sekunder, untuk data primer dilakukan pengamatan lapangan secara langsung berupa kondisi lapangan, kalibrasi pengangkutan, proses kegiatan kerja, dan hasil kegiatan, dan Dokumentasi. Untuk data primer Mengumpulkan dan menganalisis dokumen-dokumen/arsip perusahaan yang berhubungan dengan pengangkutan dan data lain untuk mendukung penelitian yang terdapat pada perusahaan khususnya pada afdeling tempat penelitian serta studi pustaka.

Untuk dapat mengetahui pengangkutan TBS harian dibutuhkan perhitungan mengenai :

a. Kapasitas Angkut/trip

$$
=\frac{\text { Jumlah TBS yang diangkut }}{\text { Jumlah Trip angkutan }}
$$

Jumlah TBS yang diangkut dapat dilihat pada Tabel 3,dan jumlah trip angkutan dapat dilihat pada Lampiran 7.

b. Jarak Tempuh/Trip

$$
=\frac{\text { jumlah jarak tempuh }}{\text { Jumlah trip angkutan }}
$$

Perhitungan Jarak tempuh menggunakan Global Posisioning system dari titik Afdeling ke Pabrik kelapa sawit.

c. Rencana produksi harian

$$
=\frac{\text { Rencana Produksi Bulanan }}{\text { Jumlah hari kerja }}
$$

Rencana produksi bulanan dan jumlah hari kerja dapat dilihat pada lampiran 2 gambar 4. Monitoring produksi. d. Jumlah Trip Harian

$$
=\frac{\text { Rencana Produksi Harian }}{\text { Kapasitas angkut }}
$$

Rencana produksi harian berdasarkan hasil perhitungan pada poin $\mathrm{C}$, kapasitas angkut berdasarkan SOP PT.DLJ yaitu 6 Ton.

e. Jarak Tempuh Harian = jumlah trip harian X jarak tempuh/trip

Jumlah trip harian berdasarkan poin $D$, jarak tempuh/trip didapat dari perhitungan pada poin $\mathrm{B}$.

f. Waktu Tempuh Harian = jumlah trip harian X waktu Tempuh Trip

Waktu tempuh harian dapat dilihat pada lampiran 3 kalibrasi pengangkutan.

g. Menghitung jumlah unit harian

$$
=\text { waktu Tempuh Harian }
$$
Jam kerja harian

Waktu tempuh harian berdasarkan perhitungan di poin $\mathrm{F}$, jam kerja harian berdasarkan SOP PT.DLJ waktu efektif kerja yaitu 7 jam.

\section{Prosedur Penelitian}

1. Mempersiapkan alat dan bahan yang akan digunakan

2. Melakukan survey lokasi untuk melihat dan menentukan tempat atau afdeling yang akan diamati dalam pelaksanaan penelitian.

3. Melakukan pengumpulan data perusahaan dan melakukan pengamatan langsung dilapangan.

\section{Analisis Data}

Analisis data penelitian ini menggunakan statistik deskriptif. Menurut Sugiono (2015), statistik deskriptif adalah statistik yang digunakan untuk menganalisis data dengan cara mendeskripsikan atau menggambarkan data yang telah terkumpulkan sebagaimana adanya tanpa bermaksud membuat kesimpulan yang berlaku secara umum. 


\section{HASIL DAN PEMBAHASAN}

Berdasarkan tabel 1 perhitungan unit harian afdeling Charlie jumlah kapasitas angkut/trip yaitu sebanyak $5.417 \mathrm{~kg}$. Jumlah ini berdasarkan jumlah TBS terangkut dibagi jumlah keseluruhan trip selama bulan Oktober, jarak tempuh 7,36 km/trip, rencana produksi 44,23 ton/hari, jumlah trip sebanyak 7 trip/hari, jarak tempuh 53,41/hari, waktu tempuh 14 jam 08 menit/hari, dan jumlah unit yang digunakan sebanyak 2 unit/hari.
Adapun standar muatan yang diberlakukan pada PT. Dwiwira Lestari Jaya yaitu 6 Ton dalam satu kali perjalanan/trip, buah yang sudah dipanen harus diangkut ke PKS dalam waktu maksimal 24 jam agar buah tidak restan. Untuk masing-masing afdeling memiliki 2 truk afdeling kegiatan pengangkutan TBS dimulai pukul 09.00 pagi sampai dengan kegiatan pengangkutan TBS selesai.

Hasil rekapitulasi produksi dan restan TBS di bulan Oktober 2020 di afdeling Charlie PT. Dwiwira Lestari Jaya ditampilkan pada tabel 3 berikut

Tabel 1. Perhitungan unit harian afdeling Charlie

\begin{tabular}{ccc}
\hline Pengangkutan TBS & Jumlah & Satuan \\
\hline Kapasitas angkut & 5.417 & $\mathrm{~kg}$ \\
Jarak Tempuh & 7,36 & $\mathrm{~km}$ \\
Rencana Produksi Harian & 44,23 & Ton \\
Jumlah Trip Harian & 7 & Trip \\
Jarak Tempuh Harian & 53,41 & $\mathrm{~km}$ \\
Waktu Tempuh Harian & $14: 00: 56$ & Jam/Menit/detik \\
Jumlah Unit Harian & 2 & Unit \\
\hline \multicolumn{2}{c}{ Sumber : Data Primer (2021) }
\end{tabular}

Tabel 3. Rekapitulasi produksi dan restan tandan buah segar.

\begin{tabular}{lcccccc}
\hline Tanggal & $\begin{array}{c}\text { jumlah } \\
\text { trip }\end{array}$ & $\begin{array}{c}\text { Produksi } \\
\text { (Janjang) }\end{array}$ & $\begin{array}{c}\text { Buah Terangkut } \\
\text { (Janjang) }\end{array}$ & $\begin{array}{c}\text { Restan } \\
\text { (Janjang) }\end{array}$ & TONASE & $\begin{array}{c}\text { Unit } \\
\text { Digunakan }\end{array}$ \\
\hline 1 Oktober & 7 & 3.127 & 2.864 & 263 & 53.96 & 3 \\
2 Oktober & 9 & 3.014 & 3.277 & 0 & 61.3 & 3 \\
3 Oktober & 8 & 3.126 & 3.126 & 0 & 56.23 & 3 \\
5 Oktober & 6 & 3.450 & 2.997 & 453 & 46.55 & 3 \\
6 Oktober & 7 & 3.442 & 3.895 & 0 & 52.07 & 3 \\
7 Oktober & 9 & 2.708 & 2.708 & 0 & 63.82 & 3 \\
9 Oktober & 6 & 2.725 & 2.725 & 0 & 49.15 & 2 \\
10 Oktober & 7 & 3.193 & 3.193 & 0 & 51.3 & 2 \\
12 Oktober & 5 & 3.083 & 2.886 & 197 & 42.56 & 3 \\
13 Oktober & 9 & 3.294 & 3.491 & 0 & 74.32 & 4 \\
14 Oktober & 7 & 3.499 & 3.499 & 0 & 54.69 & 3 \\
15 Oktober & 7 & 4.168 & 3.389 & 779 & 57.88 & 3 \\
16 Oktober & 8 & 3.601 & 4.043 & 337 & 65.87 & 6 \\
17 Oktober & 9 & 4.705 & 5.042 & 0 & 74.61 & 5 \\
19 Oktober & 9 & 4.089 & 4.089 & 0 & 71.69 & 3 \\
20 Oktober & 9 & 3.015 & 3.015 & 0 & 61.92 & 2 \\
21 Oktober & 8 & 3.523 & 3.523 & 0 & 59.66 & 2
\end{tabular}




\begin{tabular}{ccccccc}
22 Oktober & 8 & 3.762 & 3.762 & 0 & 61.25 & 2 \\
23 Oktober & 8 & 3.333 & 3.333 & 0 & 59.85 & 2 \\
24 Oktober & 7 & 2.999 & 2.999 & 0 & 57.83 & 3 \\
26 Oktober & 9 & 3.874 & 3.474 & 400 & 74.41 & 4 \\
27 Oktober & 9 & 3.865 & 4.125 & 140 & 72.19 & 3 \\
28 Oktober & 7 & 3.450 & 3.057 & 313 & 57.15 & 2 \\
29 Oktober & 3 & 1.712 & 1.625 & 618 & 21.32 & 2 \\
30 Oktober & 8 & 4.015 & 4.633 & $16 \mathrm{~kg}$ & 61.36 & 4 \\
31 Oktober & 5 & 3.120 & 2.333 & 787 & 39.01 & 3 \\
TOTAL & $\mathbf{1 9 4}$ & $\mathbf{8 7 . 8 9 2}$ & & $\mathbf{4 . 2 8 7}$ & $\mathbf{1 . 5 0 1 , 9 5}$ & \\
Rata- Rata & $\mathbf{7 . 4 6}$ & & & & 57.76 & $\mathbf{3}$ \\
\hline Suta
\end{tabular}

Sumber : Data PT. DLJ (2021)

Berdasarkan tabel rekapitulasi selama bulan Oktober 2020, jumlah produksi aktual sebanyak 1.501 .95 ton, dengan jumlah janjang 87,892 . Unit yang digunakan 2 sampai $6 \mathrm{DT} / \mathrm{hari}$, dengan total restan 4.287 janjang, dari hasil produksi tersebut jumlah trip setiap harinya bervariasi dengan jumlah terendah terdapat sebanyak 3 trip sedangkan trip terbanyak terdapat 9 trip.Dengan jumlah trip rata-rata pehari 7,4 trip/hari, dan rata-rata penggunaan DT perhari yaitu 3 unit.

Berdasarkan perhitungan rencana jumlah unit harian yang digunakan pada bulan Oktober yaitu 2 unit sudah sesuai dengan ketentuan di PT. Dwiwira Lestari Jaya sementara berdasarkan tabel 3 unit yang digunakan perhari bervariasi, 2 hingga 6 unit perhari. Jumlah keseluruhan unit yang digunakan pada bulan Oktober yaitu 15 unit, 2 DT afdeling dan 13 DT bantuan. Tidak sesuainya jumlah rencana penggunaan unit harian disebabkan oleh kondisi DT afdeling yang sering rusak dapat dilihat pada Lampiran 7.

Kondisi dump truck afdeling juga sangat mempengaruhi jumlah DT yang masuk di afdeling, apabila DT afdeling mengalami kerusakan asisten afdelling harus segera mungkin berkoordinasi dengan asisten infra untuk meminta DT bantuan dan apabila tidak ada DT infra yang standby maka digunakan DT kontraktor, penggunaan DT kontraktor dapat digunakan hingga pengangkutan selesai namun apabila banyak terdapat janjang kosong di pabrik pemanfaatan pengangkutan menggunakan DT kontraktor dilakukan saat DT kembali ke PKS setelah mengangkut janjang kosong ke afdeling. Contohnya pada tanggal 16 oktober
Total unit yang digunakan yaitu 5 unit, 1 DT afdeling dan 4 DT bantuan (2 DT infra dan 2 DT kontraktor), namun masih terdapat buah restan, hal ini dikarenakan 1 unit afdeling rusak, sehingga unit bantuan yang digunakan pada hari tersebut yang digunakan adalah DT kontraktor dan infra, setiap unit hanya melakukan pengangkutan 1 trip saja tidak sampai buah habis di TPH, kemudian 2 unit bantuan DT infra melakukan pengangkutan sebanyak 3 trip dan tidak sampai buah habis di TPH, karena setiap unit bantuan tidak melakukan pengangkutan hingga buah habis hal ini dapat menyebabkan terjadinya buah restan.

Selain kondisi DT afdeling beberapa faktor yang mempengaruhi pengangkutan sehingga dapat menyebabkan terjadinya buah tinggal dilapangan/restan yaitu prasarana pendukung di afdeling seperti kondisi jalan di beberapa blok belum dilakukan perkerasan jalan sehingga menghambat pengangkutan, topografi bukit dan titian panen yang kurang terawat dapat menghambat pemanen mengeluarkan buah ke TPH sehingga waktu memulai pemuatan cukup lama. Kurang nya tenaga muat juga dapat menghambat pemuatan TBS sehingga waktu untuk muatan TBS dibutuhkan waktu lebih lama dan Kondisi PKS juga dapat mempengaruhi pengangkutan TBS apabila terjadi kerusakan pada mesin pabrik ataupun banyaknya buah inti dan buah masyarakat yang mengakibatkan loading ramp penuh sehingga terjadi antri di PKS, hal ini dapat mempengaruhi proses pengangkutan buah terhambat apabila tidak ada DT bantuan dapat menyebabkan pengangkutan terhambat dan terjadi restan.

Curah hujan pada bulan Oktober sebesar $245 \mathrm{~mm}$. Menurut Oldeman et al, (1980), 
suatu bulan dikatakan bulan basah apabila mempunyai curah hujan bulanan lebih besar dari $200 \mathrm{~mm}$ dan dikatakan bulan kering apabila curah hujan bulanan lebih kecil dari $100 \mathrm{~mm}$. Dari data pada bulan Oktober termasuk bulan basah atau sering terjadi hujan berdasarkan Lampiran 3 data curah hujan pada bulan oktober terjadi 19 hari hujan, curah hujan yang tinggi dapat mempengaruhi pengangkutan Tandan Buah Segar, hal ini dikarenakan dapat menyebabkan akses jalan rusak sehingga pengangkutan terhambat pengumpulan TBS di TPH pada daerah yang memiliki topografi bukit akan sulit mengeluarkan buah, hal ini dapat diatasi dengan melakukan rawat jalan/rawat sisip pada jalan yang rusak.

Pada praktiknya, pengangkutan TBS di afdeling Charlie estate DLJ 1 menggunakan kendaraan jenis Dump Truck (DT). Berdasarkan kebijakan kebun pada pembagian DT untuk setiap devisi sebanyak 2 Unit dengan jumlah keseluruhan unit di estate DLJ 1 yaitu 35 unit DT (14 DT afdeling 21 DT infra), masing masing unit memiliki anggota tenaga muat berjumlah 3 orang dengan total anggota muat pada afdeling Charlie sebanyak 6 orang, Kegiatan pengangkutan meliputi pengangkutan TBS dan Brondolan dari TPH ke unit. Pekerjaan Transport dinyatakan selesai jika buah hasil panen yang ada di TPH telah diangkut semua ke PKS, sehingga tidak ada batasan waktu untuk pemuatan dalam bekerja, namun jika terjadi buah restan untuk pengangkutan hari selanjutnya diharuskan untuk mengangkut buah restan terlebih dahulu atau melakukan pengangkutan dijam lebih awal.

Adapun upaya yang dapat dilakukan untuk meminimalisir buah restan dilapangan adalah perawatan rutin pada DT afdeling dan memaksimalkan jumlah muatan TBS pada setiap tripnya, perawan prasarana kebun seperti pengecekan titian panen apabila terdapat titian panen yang rusak segera diperbaiaki agar proses pengeluaran buah tidak terhambat yang mengakibatkan terlambatnya pemuatan buah ke truk, pada jalan laluan DT yang rusak segera dilakukan sisip jalan atau perkerasan jalan sehingga apabila terjadi hujan tidak menjadi kendala atau menghambat proses pengangkutan, tukang muat wajib mengenakan Alat Pelindung Diri (APD) lengkap agar menghindari kecelakaan kerja yang menyebabkan karyawan tidak masuk kerja atau kurangnya tenaga muat yang mengakibatkan dibutuhkan waktu lebih lama pada proses muat buah dari TPH ke DT, asisten afdeling sebaiknya segera berkoordinasi dengan asisten infra apabila salah satu DT afdeling mengalami kerusakan atau kurangnya DT di afdeling agar sebelum kegiatan dimulai asisten infra dapat menambahkan DT bantuan selama proses pengangkutan hingga selesa, menambah DT apabila antrian PKS cukup lama dan memualai pengangkutan tepat waktu atau memulai pengangkutan pada pukul 9 pagi.

\section{KESIMPULAN}

Dari penelitian evaluasi pengangkutan tandan buah segar kelapa sawit terhadap buah restan pada afdeling Charlie di PT. Dwiwira Lestari Jaya, maka dapat disimpulkan, jumlah unit pengangkut TBS tiap afdeling sesuai dengan perhitungan kebutuhan yaitu dua unit pengangkut TBS, berdasarkan realisasi di lapangan penggunaan unit perhari lebih dari 2 atau belum sesuai dengan perhitungan kebutuhan serta beberapa hal yang mempengaruhi kinerja pengangkutan sehingga menyebabkan buah restan yaitu kondisi alat angkut, kondisi PKS, jumlah tenaga kerja angkut, kondisi jalan, dan curah hujan.

\section{DAFTAR PUSTAKA}

Anonim. 2004. Pedoman Dasar Instruksi Kerja PT. Bakrie Pasaman Plantation.

Anonim. 2007. BPM Seri Budidaya Tanaman Kelapa Sawit. LPP Kampus Medan.

Anonim. 2009. Tanaman Kelapa Sawit. CV. Yrama Widya. Bandung.

Amalia, S, I, A.Ayiek Sih Sayekti, Listiyani. 2016. Kajian Transportasi Angkut TBS Kelapa Sawit di PT. Perkebunan Nusantara II Desa Bnangun, Kecamatan Gunung Malela, Kabupaten Simalungan, Provinsi Sumatra Utara. Vol. 1. No. 1 (2016).

Dhani S.R. 2014. Manajemen Panen dan Transportasi Kelapa Sawit (Elaesis Guineensis Jacq) di sungai Bahaur Estate, PT Windu Nabat Indo Abadi, 
Kalimantan Tengah. Fakultas Pertanian Instusi Pertanian Bogor, Bogor.

Fadilah, F. 2013. Efektifitas Pengakutan Tandan Buah Segar Kelapa Sawit (Elaeis guineensis Jacq) di Kebun Sei Rokan PT. Perkebunan Nusantara V. Tugas Akhir Mahasiswa Sekolah Tinggi IImu P A P. Medan.

Fauzi Y, Yustina E W, Iman S, dan Rudi H. 2008. Kelapa Sawit. Penebar Swadaya, Jakarta.

Fauzi Y. 2012, Kelapa Sawit, Edisi Revisi, Penebar Swadanya, Jakarta.

Hudori. M. 2016. Perencanaan Kebutuhan Kendaraan Angkutan Tandan Buah Segar (TBS) di Perkebunan Kelapa Sawit. Malikussaleh Industri Enginering Vol.5 No.1 (2016) 22-27.

Lukito P, L, dan Sudradjat. 2017. Pengaruh Kerusakan Buah Kelapa Sawit terhadap Kandungan Free Fatty Acid dan Rendemen CPO di Kebun Talisayan 1 Berau. Vol. 5 No. 1 (2017) 37-44.

Oldemen, R.L., Irsal Las, and Muladi. 1980. The Agro-climatic Maps of Kalimantan, Maluku, Irian Jaya, and Bali West and East Nusa Tenggara Contrib. No.60. Bogor: Centr. Res. Inst, Agrc. Bogor

Pahan, I.2008. Panduan Lengkap Kelapa Sawit. Penebar Swadaya. Jakarta.

Qamariah N, dan Gusti Rokhmiati I. 2019. Estimasi Produksi Tandan Buah Segar Kelapa Sawit (Elaeis guineensis Jacq.) dl PT Hasnur Citra Terpadu. Vol. 7 No. 2 (2019).

Saragi G, H. 2019. Evaluasi Sistem Pengelolaan Pengangkutan Tandan Buah Segar Kelapa Sawit (Studi Kasus di PT. Sentosa Kalimantan Jaya)KKecamatan Derawan Kbupatten Berau Provinsi Kalimantan Timur. Program Studi Pengelolaan Perkebunan, Samarinda. Hal: 11

Setyamidjaja D. 2006. Seri Budidaya Kelapa Sawit, Teknik Budi Daya, Panen, Pengolahan, Yogyakarta.

Sukamto. 2008. Kiat Meningkatkan Produktivitas dan Mutu Kelapa Sawit. Jakarta. Penebar Swadaya. 83 hal.

Sugiyono. 2015. Metode Penelitian Kombinasi (Mix Methods). Bandung: Alfabeta.

Suharmi Arikunto dan Cepi safruddin abdul jabar, 2018 evaluasi program pendidikan. PT bumi aksara jakarta 